Mens

revue d'histoire intellectuelle de l'Amérique française

\title{
" Le germe de la liberté » : les républicains du Bas-Canada et les révolutions européennes de 1848
}

\section{Dzavid Dzanic}

Volume 9, numéro 1, automne 2008

URI : https://id.erudit.org/iderudit/1022820ar

DOI : https://doi.org/10.7202/1022820ar

Aller au sommaire du numéro

Éditeur(s)

Centre de recherche en civilisation canadienne-française

ISSN

1492-8647 (imprimé)

1927-9299 (numérique)

Découvrir la revue

Citer cet article

Dzanic, D. (2008). « Le germe de la liberté » : les républicains du Bas-Canada et les révolutions européennes de 1848. Mens, 9(1), 35-80.

https://doi.org/10.7202/1022820ar
Résumé de l'article

Les rouges ont généralement été considérés comme un groupe libéral s'opposant à l'Acte d'Union. Plus récemment, certains spécialistes ont remis en question cette interprétation en suggérant qu'ils aient plutôt été républicains. En adoptant un point de vue transatlantique et en analysant l'interprétation que les rouges ont faite des révolutions européennes de 1848, cet article montre que ceux-ci adoptèrent bel et bien une idéologie républicaine modérée à la fin des années 1840, idéologie qu'ils exprimèrent d'abord à travers le contexte européen. Ils en vinrent ensuite à réclamer l'introduction d'institutions républicaines au Bas-Canada, incluant l'abolition du gouvernement responsable et l'adoption du principe de la souveraineté populaire. 


\title{
« LE GERME DE LA LIBERTÉ » : LES RÉPUBLICAINS DU BAS- CANADA ET LES RÉVOLUTIONS EUROPÉENNES DE $1848^{1}$
}

\author{
Dzavid Dzanic \\ Département d'histoire \\ University of British Columbia
}

\section{Résumé}

Les rouges ont généralement été considérés comme un groupe libéral s'opposant à l'Acte d'Union. Plus récemment, certains spécialistes ont remis en question cette interprétation en suggérant qu'ils aient plutôt été républicains. En adoptant un point de vue transatlantique et en analysant l'interprétation que les rouges ont faite des révolutions européennes de 1848, cet article montre que ceux-ci adoptèrent bel et bien une idéologie républicaine modérée à la fin des années 1840 , idéologie qu'ils exprimèrent d'abord à travers le contexte européen. Ils en vinrent ensuite à réclamer l'introduction d'institutions républicaines au Bas-Canada, incluant l'abolition du gouvernement responsable et l'adoption du principe de la souveraineté populaire.

\section{Abstract}

Les Rouges have traditionally been characterized as a liberal group opposed to the Act of Union and Responsible Government, but scholars have recently hinted at the possibility that they were in fact republicans. By adopting a transatlantic perspective and analysing Les Rouges' interpretation of the 1848 European Revolutions, this article shows that they came to adopt a moderate republican ideology by the end of 1840s, which they first articulated through the European context. Moreover, Les Rouges argued for the need to incorporate republican 
institutions in Lower Canada by abolishing the Responsible Government and relying on the principle of popular sovereignty.

En janvier 1847, lord Elgin arriva au Canada à titre de gouverneur général. À ce moment, le gouvernement britannique était disposé à accorder une plus grande autonomie à ses colonies d'Amérique du Nord. Elgin fut chargé par le gouvernement impérial d'introduire une réforme cruciale au Canada : le gouvernement responsable ${ }^{2}$. Sous le nouveau régime, Elgin devait nommer au Conseil exécutif les représentants élus qui avaient la confiance de la Chambre et accepter les lois adoptées par l'Assemblée concernant les questions locales ${ }^{3}$. Les réformistes coloniaux ayant remporté les élections de 18471848, le gouverneur appela Louis-Hippolyte La Fontaine, dont l'ascendant sur la politique canadienne-française était à son plus fort, et Robert Baldwin à siéger au Conseil exécutif le 11 mars $1848^{4}$. Le nouveau gouvernement tirait ainsi sa force de l'union des réformistes anglophones et francophones.

Bien que l'avènement du gouvernement responsable ait résolu un des problèmes les plus urgents de la politique coloniale en harmonisant la relation entre les pouvoirs exécutif et législatif, tous les Canadiens ne furent pas satisfaits. L'incendie du parlement par les Tories, frustrés de constater l'influence croissante des Canadiens français, et l'émergence d'un mouvement favorisant l'annexion du Canada aux États-Unis (les deux événements s'étant produits en 1849) témoignaient du mécontentement qui sévissait au sein de certains groupes de Canadiens anglais. Parallèlement, les Canadiens français - dont certains signèrent le manifeste annexionniste - étaient également divisés. Louis-Joseph Papineau, l'ancien leader du Parti patriote qui s'était rebellé contre la domination britannique en 1837, retourna à l'Assemblée en 1848. Il représentait l'opinion d'une minorité radicale, les rouges, largement composée 
de jeunes journalistes associés au journal L'Avenir et qui comptait aussi dans ses rangs son neveu Louis-Antoine Dessaulles. Les rouges s'opposaient à l'Acte d'Union, qui avait fusionné le Haut et le Bas-Canada pour former la Province du Canada en $1841^{5}$, et au gouvernement responsable, jugeant que ces deux réformes étaient préjudiciables à la liberté politique des Canadiens français.

Les historiens ont largement admis l'opinion que les partisans de La Fontaine et de Papineau constituaient deux branches du parti réformiste libéral. Par exemple, Jean-Paul Bernard ne remet pas en question l'enthousiasme de L'Avenir et de Papineau pour le libéralisme en $1848^{6}$. Il se contente d'affirmer que «le parti rouge, [...] lui, était peut-être un peu plus à gauche ${ }^{7} »$. Adoptant le même point de vue, Fernande Roy explique que «[m]algré l'étiquette, les rouges ne sont pourtant pas des révolutionnaires, mais bien des libéraux ${ }^{8} »$. De son côté, Yvan Lamonde dit des jeunes fondateurs de L'Avenir qu'ils étaient «la jeunesse libérale" » qui, avec Papineau et Dessaulles, voulait « réanimer le souffle libéral» et " conjuguer libéralisme et nationalité ${ }^{10}$ ». Lamonde a également écrit une excellente biographie de Dessaulles, dans laquelle celui-ci est décrit comme un seigneur libéral et anticlérical $^{11}$. Dans le présent article, nous revisitons cette interprétation de l'idéologie rouge. À partir d'une relecture du journal L'Avenir, nous entendons démontrer que même si les rouges se disaient libéraux, ils en vinrent à adopter une idéologie républicaine en 1848.

L'apparition initiale du républicanisme au Bas-Canada, ainsi que sa persistance en 1848, fut influencée et encouragée par le développement du républicanisme dans le monde atlantique. Le développement du monde atlantique comme cadre d'analyse historique a permis aux historiens de revisiter plusieurs questions sociales et économiques en Europe, en 
Afrique et dans les Amériques, et ce pour la période allant des premiers contacts entre l'Europe et l'Amérique à la période révolutionnaire de la fin du XVIII ${ }^{e}$ siècle $^{12}$. Un des champs de la discipline historique qui a grandement bénéficié du développement de ce cadre a été l'histoire politique et intellectuelle. À cet égard, l'apport des Bernard Bailyn, Gordon S. Wood et J. G. A. Pocock ne peut être passé sous silence, ces derniers ayant été les pionniers de l'étude des idéologies dans une perspective transatlantique ${ }^{13}$. Ce sont eux qui ont révélé l'existence d'un républicanisme atlantique, à tout le moins dans le monde atlantique anglo-américain.

Bien que le cadre atlantique n'ait pas été pensé pour le $\mathrm{XIX}^{\mathrm{e}}$ siècle, des spécialistes travaillant sur les idéologies au Bas-Canada le lui ont appliqué et ont réévalué l'influence du républicanisme sur la colonie dans la première moitié de ce siècle. Les rébellions de 1837 et leurs causes, par exemple, ont été examinées à travers un prisme républicain ${ }^{14}$. Bien que les rouges aient été les héritiers des patriotes, les chercheurs les ont rarement considérés comme formant un mouvement républicain. Stéphane Kelly fait ici figure d'exception, ayant déjà expliqué que ceux qui écrivaient pour L'Avenir articulaient un discours relevant du républicanisme agraire, sans préciser néanmoins comment et pourquoi ils avaient adopté cette idéologie ${ }^{15}$. À cela, il faut ajouter que l'influence du contexte transatlantique sur les rouges n'a presque jamais été étudiée. La présente étude enrichit les points de vue précédents en analysant comment et sous quelles formes spécifiques le républicanisme a subsisté dans le Bas-Canada et en est venu à être influencé par le flux d'informations transatlantiques. Même si une étude des rouges en 1848 et au début de 1849 se situe chronologiquement hors du cadre atlantique, nous soutenons que le républicanisme a continué à exister au Bas-Canada après les rébellions de 1837-1838 et qu'il a été exprimé 
dans L'Avenir à travers l'analyse de la situation révolutionnaire en Europe, dont le journal obtenait des nouvelles par les bateaux à vapeurs transatlantiques.

Nous exposons dans un premier temps les principaux sujets politiques traités dans L'Avenir au début de 1848 . Nous montrons ensuite comment ces derniers ont conduit le journal au républicanisme en procédant à une analyse textuelle interne. Notre méthode s'inspire de la théorie de la mise en intrigue (emplotment) de Hayden White, selon laquelle le narrateur impose un sens aux événements qu'il raconte en privilégiant certains éléments plutôt que d'autres ${ }^{16}$. En adoptant cette méthode, nous pouvons mettre en lumière jusqu'à quel point le républicanisme des rouges a été forgé par leur analyse des révolutions européennes de 1848 . Pour démontrer la validité de notre propos, nous étudions parallèlement la mise en intrigue, non républicaine celle-là, des événements de février 1848 publiée par le journal conservateur canadien-français La Minerve. Nous abordons enfin le processus par lequel les penchants républicains des rouges se sont plus tard manifestés et ont mûri dans le cadre du contexte révolutionnaire européen, qui a permis à L'Avenir d'exprimer des idées qui auraient autrement été considérées comme subversives dans le cadre du Bas-Canada ${ }^{17}$.

\section{L'Avenir et sa mise en intrigue émancipatrice des révolutions européennes de 1848}

Jean-Baptiste-Éric Dorion et George Butchelor fondèrent le journal bas-canadien L'Avenir en juillet 1847. Ils le produisaient avec un groupe de treize jeunes hommes de Montréal, presque tous âgés de moins de $25 \mathrm{ans}^{18}$. Si l'éducation était initialement le centre d'intérêt premier du journal, le retour de Papineau à la vie politique en 1847 et la nomination temporaire de Louis-Antoine Dessaulles, son neveu, 
comme rédacteur en $1848^{19}$ ramenèrent la question politique à l'avant-plan. L'Avenir publia en janvier 1848 le Manifeste aux électeurs des comtés de. Huntingdon et de Saint-Maurice de Papineau et se dit d'accord avec lui sur les problèmes causés par l'Union, sans pour autant faire sienne sa répugnance pour le gouvernement responsable et sa demande pour l'abrogation immédiate de l'Acte d'Union. À ce moment, le journal se considérait encore comme appartenant à l'ensemble du Parti réformiste canadien-français ${ }^{20}$. Néanmoins, les écrits et discours de Papineau et de Dessaulles continuèrent de paraître régulièrement dans L'Avenir et leurs idées furent rapidement adoptées par les jeunes journalistes en 1848, quand le Parti libéral canadien-français se divisa entre ceux qui s'étaient ralliés à l'Union (sous la direction de La Fontaine) et ceux qui s'y opposaient, ainsi qu'à tout ce qui y était associé, incluant le gouvernement responsable ${ }^{21}$.

Peu après le retour de Papineau à l'Assemblée au début de 1848, L'Avenir commença à s'en prendre directement à l'Acte d'Union et au gouvernement responsable. Dans un article intitulé "L'Union », Dessaulles, écrivant sous le pseudonyme Anti-Union, dénonça l'exploitation financière et politique des Canadiens français par les moyens fournis par l'Union, qui soumettait « tous les moyens du gouvernement, les charges d'honneur et de profits des deux provinces au contrôle absolu, irrésistible, d'une minorité réelle du peuple afin de lui assurer par là la suprématie sur la majorité réelle ${ }^{22} »$. Sa cible principale ici était la représentation à l'Assemblée : malgré le poids démographique supérieur des Bas-Canadiens, le Haut et le Bas-Canada avaient 42 sièges chacun. Indigné, Dessaulles lançait à ses compatriotes : «Concourons donc avec lui [Papineau] à la destruction de l'union des deux provinces ${ }^{23}$. " S'attaquant ensuite aux récentes réformes, Dessaulles, écrivant maintenant sous le pseudonyme Campa- 
gnard, se montra d'accord avec la description de Papineau du gouvernement responsable comme étant utilisé contre les intérêts canadiens-français : "C'est au moyen d'une chimère, qualifiée du titre pompeux de gouvernement responsable qu'on vous a fait accepter l'Union dans le seul but de vous anéantir politiquement et de vous nullifier moralement ${ }^{24}$. »Comme l'attestent ces déclarations, L'Avenir se radicalisa nettement quand l'influence de Dessaulles s'accrut en février 1848.

Le cadre politique n'était cependant pas le seul souci de L'Avenir: l'accent croissant qu'il mettait sur la corruption politique, le droit de la majorité à gouverner et les effets abominables de la manipulation monarchique indique que Dessaulles orientait graduellement le journal dans une direction républicaine. Quentin Skinner explique que selon la conception républicaine de la liberté politique, la liberté est directement liée à l'autonomie gouvernementale et à la capacité de chaque individu dans la société de participer sans restriction à la vie politique, laquelle prospère lorsque l'individu libre se consacre au service public et à la promotion des vertus civiques ${ }^{25}$. En conséquence, les gens qui vivent dans un tel «État libre » bénéficient de «la grandeur et de la richesse civiques». En échange, l'État assure «la liberté personnelle, comprise au sens ordinaire signifiant que chaque citoyen demeure libre de tout élément de contrainte $[. .$.$] et demeure en$ conséquence libre de poursuivre les fins qu'il a choisies ${ }^{26} \mathrm{~m}$.

De la même manière, Per Mouritsen met en lumière dans sa toute récente réévaluation de la littérature républicaine la très importante croyance républicaine voulant que «la liberté ne [pouvait] être obtenue, et obtenue de façon assurée, que dans le sens collectif où elle s'exprim[ait] dans des lois (constitutionnelles) liant tout le monde $[\ldots]^{27}$ ». Poursuivant sur cette lancée, Mouritsen présente ensuite les quatre mécanismes grâce auxquels « l'activité civique jouait un rôle dans la li- 
berté commune ", ou, en d'autres mots, comment l'exercice des obligations civiles par chacun des citoyens favorisait la liberté de toute la population. Premièrement, l'établissement de l'« artifice institutionnel et légal de la république » signifiait que le citoyen protégeait l'État et était protégé par lui des menaces internes et externes. Deuxièmement, la création d'un espace civique sûr garantissait à tous les citoyens l'existence d'une attente mutuelle quant au respect des droits de chacun au sein de l'État. L'autonomie politique impliquait donc entre autres le respect du droit inaliénable à la sécurité privée dont devaient jouir tous les citoyens. Troisièmement, l'existence d'une autonomie politique au sein de l'État sous-entendait la validation temporelle des décisions gouvernementales qui devaient exprimer la volonté du peuple. Et enfin, l'identité civique, ou le patriotisme, se manifestait sous diverses formes, mais toujours en lien avec l'identité d'un groupe souhaitant préserver sa liberté commune ${ }^{28}$. Ces quatre mécanismes expliquent comment la république devait fonctionner, c'est-à-dire soutenir la liberté populaire et l'autonomie gouvernementale. Même si ces caractéristiques correspondent de près à l'idéologie énoncée par L'Avenir au début de 1848, les connotations contemporaines négatives qu'avait le républicanisme dans le Bas-Canada et le souvenir des rébellions de 1837 et de leurs conséquences pour les Canadiens français ont amené L'Avenir à exprimer son républicanisme par des voies détournées.

Ainsi, les rouges n'étaient peut-être pas aussi «libéraux » que l'historiographie l'a laissé entendre. Malgré les ressemblances entre le républicanisme et le libéralisme - pensons par exemple à l'importance que ces deux idéologies accordent au règne de la loi -, ils conçoivent différemment les relations entre l'individu et l'État. John Gray a décrit en ces 
termes les concepts libéraux clés que partageaient toutes les variantes historiques du libéralisme:

[Le libéralisme] est individualiste, en ce qu'il affirme la primauté morale de la personne contre les prétentions de toute collectivité sociale ; égalitaire, dans la mesure où il attribue à tous les hommes le même statut moral et nie la pertinence pour l'ordre juridique ou politique de différences de valeur morale entre les êtres humains ; universaliste, affirmant l'unité morale de l'espèce humaine [...], et mélioriste, en ce qu'il affirme la corrigibilité et l'améliorabilité de toutes les institutions sociales et de l'organisation politique ${ }^{29}$.

La différence cruciale, par conséquent, entre le républicanisme et le libéralisme est que le premier met davantage l'accent sur la collectivité, alors que le second privilégie l'individu. À la lumière de cette distinction, il devient clair qu'en février 1848 L'Avenir a commencé à tenir un discours à tendance républicaine. Sa principale affirmation, soit que l'Acte d'Union et le gouvernement responsable instauraient et maintenaient en place un système gouvernemental ne parvenant pas à refléter l'opinion des gens, correspondait à l'idéal républicain d'un gouvernement étroitement contrôlé par les citoyens. Cet enthousiasme naissant pour les idées républicaines fut d'abord exprimé ouvertement dans L'Avenir par une analyse de la révolution française de 1848.

Peu après s'être rangés aux côtés de Papineau, les jeunes collaborateurs radicalisés de L'Avenir commencèrent à recevoir les nouvelles des révolutions d'Europe, lesquelles parvenaient plus régulièrement grâce à l'apparition des navires à vapeur. La vague révolutionnaire qui déferla sur l'Europe en 1848 commença en Sicile, où le roi fut forcé d'établir une constitution après les insurrections populaires de janvier. Cela se produisait dans le contexte plus général de mauvaises 
récoltes de pommes de terre à travers l'Europe, où une récession générale s'était également produite en 1847. En février 1848, le roi de Piémont-Sardaigne et le grand-duc de Toscane accordèrent des constitutions à leurs sujets. À la fin du mois, une véritable révolution éclata en France, lancée et menée surtout par la classe ouvrière, la petite bourgeoisie, la Garde nationale et les étudiants universitaires. Les combats débutèrent le 22 février et prirent fin le 24, quand Louis-Philippe abdiqua et qu'un gouvernement provisoire fut formé. La république fut proclamée par Alphonse de Lamartine le 25 février. En mars 1848, le peuple se souleva également contre les gouvernements en Italie, en Allemagne, dans l'empire d'Autriche, en Belgique, aux Pays-Bas et en Scandinavie. Paris fut de nouveau parsemé de barricades en juin à cause de la fermeture des Ateliers nationaux ${ }^{30}$, mais le gouvernement réussit à maintenir l'ordre, en grande partie grâce aux efforts du général Cavaignac, qui fut nommé premier ministre ce même mois. Des troubles secouèrent une bonne partie de l'Europe pendant le reste de $1848^{31}$. Le premier signe majeur d'affaiblissement du zèle révolutionnaire et républicain en France fut la victoire de Louis-Napoléon Bonaparte à l'élection présidentielle de décembre 1848. En janvier 1849, il nomma des ministres conservateurs qui supprimèrent immédiatement la Solidarité républicaine, groupe de députés de gauche à l'Assemblée nationale française ${ }^{32}$. Le retour des conservateurs au pouvoir se fit graduellement à travers l'Europe et, à la fin de 1851, la plupart des États ${ }^{33}$ avaient rétabli des principes gouvernementaux monarchiques et rejeté les concessions consenties lors des soulèvements ${ }^{34}$.

Suivant attentivement et analysant les conflits, L'Avenir se rangea du côté des révolutionnaires dès le début et interpréta les révolutions comme des mouvements d'émancipation. Même si le contexte politique bas-canadien le forçait 
à autocensurer son républicanisme naissant, L'Avenir put se servir de l'exemple français pour exprimer sa vision négative de la monarchie sans critiquer directement l'empire britannique. Pour analyser la structure textuelle interne des articles de L'Avenir sur les révolutions européennes de 1848, les théories de constitution d'arguments et de mise en intrigue de Hayden White sont utiles. White appelait mise en intrigue le processus par lequel un auteur met en lumière certains éléments textuels spécifiques dans le but de leur attribuer un sens. Il soutenait que les mises en intrigue correspondent à des tropes, tels que le drame ou la comédie, qui structurent le type de sens qui est imposé aux événements ${ }^{35}$. La présente étude s'inspire de la théorie de la mise en intrigue de White, sans toutefois chercher à découvrir systématiquement les détails de la mise en intrigue dans les articles sur les révolutions européennes. La présente analyse se contente d'indiquer les points généraux qui reviennent régulièrement dans les articles et lie ces points soulignés aux tropes structurant l'orientation idéologique de L'Avenir. Comme il n'existe toujours pas d'étude sur l'information exacte dont pouvaient disposer les journaux bas-canadiens en 1848-1849, il est évidemment impossible de déterminer avec précision la manière dont L'Avenir sélectionnait et mettait en lumière les événements. Cela ne nous empêche toutefois pas de faire notre analyse, car la nature répétitive des stratégies de mise en intrigue de L'Avenir renforce le lien entre son idéologie et son orientation éditoriale. L'argument est également renforcé en examinant comment le conservatisme de La Minerve a influencé sa mise en intrigue des événements parisiens de manière inverse au lien entre l'idéologie républicaine de L'Avenir et la mise en intrigue émancipatrice.

L'Avenir a publié le premier article sur la révolution en France le 22 mars 1848. Le rédacteur avoua alors qu'il avait 
dû reconstituer le cours des événements à partir de sources d'information limitées ${ }^{36}$. Il mit en intrigue la révolution de février 1848 comme un mouvement d'émancipation en trois étapes distinctes : premièrement, un peuple opprimé s'est vu refuser sa liberté naturelle par l'État; deuxièmement, la situation oppressive a abouti à un point d'ébullition où la violence a éclaté et où la monarchie a été renversée ; troisièmement, le calme général a suivi la révolte populaire une fois les causes de l'insurrection éliminées avec succès et la liberté rendue à la nation.

Pour les rédacteurs de L'Avenir, les principales causes de la révolution étaient le manque de respect de la monarchie pour la constitution et les réformes progressistes, la corruption des politiciens, qui ne tenaient aucun compte des besoins du peuple, et l'incapacité des ministres à échapper à l'influence négative de la diplomatie anglaise. Selon le rédacteur, le gouvernement français avait tenté de dissimuler la corruption et d'étouffer l'opinion publique en interdisant les réunions publiques, par exemple les banquets et les dîners entre réformistes. Cette mesure tyrannique incita Louis-Adolphe Thiers, député à l'assemblée, et Camille Odillon-Barrot, un des organisateurs du banquet de $1847^{37}$, à exprimer leur indignation et à annoncer la possibilité d'une révolution. Les " chefs du parti de la réforme " publièrent également une communication le 21 février, pressant tous les réformistes à se rencontrer pour un banquet dans le $\mathrm{XII}^{\mathrm{e}}$ arrondissement de Paris. L'Avenir indiquait que la réunion proposée avait pour objectif «l'exercice légal et paisible d'un droit constitutionnel, le droit de faire des assemblées politiques, sans lequel le gouvernement représentatif n'est qu'une dérision ». Par la suite, des groupes de curieux envahirent les rues de Paris et les soldats furent mobilisés pour maintenir l'ordre. Les foules ne tardèrent pas à converger vers la Chambre des députés, où 
l'opposition proposa un acte d'accusation contre le gouvernement. Entre autres critiques, elle accusait le gouvernement d'avoir injustement corrompu le "gouvernement représentatif ", violé les garanties de liberté et provoqué une agitation populaire en rejetant tout ce que les deux révolutions précédentes avaient réalisé. À ce moment, les spectateurs qui voulaient simplement être témoins du débat furent dispersés avec vigueur par les soldats. En réponse, des barricades furent érigées dans tout Paris et un jeune homme déclencha les hostilités en tirant froidement sur un commandant qui protégeait l'hôtel de François Guizot, le véritable chef du gouvernement. Les soldats tirèrent à leur tour, tuant un bon nombre de personnes. Les foules réagirent alors en se rassemblant et en exigeant une revanche. Le lendemain, d'autres barricades furent élevées alors que les soldats tentaient de redevenir maitres des rues.

Le rédacteur de L'Avenir se concentra alors sur les événements survenus à la Chambre des députés, affirmant que le roi avait demandé au comte Louis-Mathieu Molé, conservateur modéré sympathique au libéralisme ${ }^{38}$, de former un gouvernement, mesure qui fut accueillie de façon mitigée. Le lendemain, le roi abdiqua et lorsqu'on proposa à la Chambre de confier la régence à la duchesse d'Orléans (la mère du roi), tumulte et confusion s'ensuivirent, et l'on cria : «Il est trop tard. » Par la suite, un gouvernement provisoire fut formé sous direction républicaine et les masses agitées s'écrièrent : "Vive la république. » Le trône de l'ex-roi fut trainé dans les rues de Paris et finalement brûlé. « Si [...] il ne se fût pas servilement traîné de loin sur les pas de la diplomatie anglaise, écrivit $L^{\prime} A v e$ nir avec émotion, Louis-Philippe serait peut-être encore sur le trône. » Le 25 février, le gouvernement provisoire proclama la république et "[l]'ordre [était] à peu près rétabli ». Le cycle de la mise en intrigue émancipatrice prit fin à ce moment ${ }^{39}$. 
La structure imposée à ces événements indiquait que L'Avenir avait recours à un ensemble de critères républicains pour évaluer la justification de la violence. Insistant sur la corruption du pouvoir royal, le rédacteur du journal souligna le moment où la dernière mesure de Louis-Philippe, qui proposait la duchesse d'Orléans à la Chambre, fut fortement rejetée. «Il est trop tard » est le mot d'ordre qui déboucha sur la révolution. Dès lors, le peuple, qui doit s'administrer lui-même et jouir de sa liberté dans un système républicain, décida de réclamer ses droits avec force. Une fois la population unie et armée, la seule issue possible était une république où seraient restaurés ses droits et libertés. La présentation faite par L'Avenir du dénouement révolutionnaire impliquait que le retour à la paix était inévitable. Dès que la violence populaire eut atteint ses objectifs, le calme et la tranquillité revinrent dans un cadre républicain.

Les trois principaux facteurs ayant causé la révolution en France selon L'Avenir étaient directement liés à son idéologie républicaine et à la situation politique bas-canadienne. En soulignant que l'incapacité de réformer le gouvernement, la corruption monarchique et l'ingérence constante des Anglais dans les affaires françaises avaient sonné le glas de la monarchie de Juillet, L'Avenir indiquait implicitement qu'il se souciait de problèmes parallèles dans le Bas-Canada. Le républicanisme voulait qu'une république protège ses citoyens des menaces internes et externes et, de l'avis de L'Avenir, les Canadiens français qui siégeaient à l'Assemblée ne pouvaient y parvenir avec le gouvernement responsable. Ce dernier était une réforme négative, car il était fondé sur la corruption et la reconnaissance de la puissance du pouvoir exécutif, officiellement détenu par le gouverneur général. En acceptant les positions gouvernementales, les politiciens canadiens-français acceptaient en fait les conditions antirépublicaines de l'Union. 
Un collaborateur de L'Avenir expliquait que l'assemblée, « qui devrait être le sanctuaire de la vertu, le temple de l'intégrité, de l'indépendance et du désintéressement, est convertie par le ministère lui-même en un club d'intrigants et devient une source de corruption ${ }^{+1}$ ». En outre, l'ingérence anglaise dans les affaires du Bas-Canada était due à la présence du gouverneur général, qui renforçait les dispositions politiques antirépublicaines et représentait l'influence extérieure corruptrice sur le Bas-Canada. Toutes les énergies éditoriales de L'Avenir portaient sur l'explication de ces problèmes à la population et encourageaient les Canadiens français à s'unir en un mouvement qui les émanciperait sur le plan politique. Cet espoir se greffait manifestement sur la révolution en France.

La Minerve, à l'opposé, publia très peu de commentaires positifs sur la révolution française de 1848, et la mit plutôt en intrigue comme un événement dans une grande mesure inutile et regrettable. Le 20 mars 1848 , deux jours avant que L'Avenir ne publie son compte rendu de la révolution en France, La Minerve offrit sa propre version. Elle commençait par un titre portant sur la famille royale et le roi : « Révolution en France. Louis-Philippe detroné [sic]. La famille royale refugiée [sic] en Angleterre. » Le rédacteur mettait à profit les petits détails qu'il avait à sa disposition pour brosser un sombre tableau de Paris. La ville redevenait un théâtre révolutionnaire, le sang coulait, le parti antimonarchique proclamait la république, un grand nombre de Parisiens étaient tués lors d'altercations, le Palais royal était saccagé et les routes conduisant à Paris étaient coupées. Voilà quel fut le premier résumé factuel de la révolution en France dans La Minerve.

Le rédacteur montra ensuite une certaine sympathie pour le mouvement révolutionnaire populaire, mais il n'en continua pas moins à présenter toute la situation comme déplorable. Par exemple, il était d'avis que la bravoure de La- 
moricière, un général attaqué par les révolutionnaires, était malencontreuse parce qu'il participait à un conflit où «des deux côtés le sang français a coulé ». Le motif de la futilité revenait avec force dans la description. Contrairement à L'Avenir, qui soulignait l'injustice du gouvernement quand il interdisait les banquets publics, La Minerve expliquait que « le gouvernement, par l'organe du ministre de la justice, avait annoncé qu'il empêcherait ces manifestations "dangereuses pour l'ordre public" ». Sans prendre le temps d'évaluer les résultats politiques de la révolution, La Minerve indiquait : "Le contrecoup de la révolution française s'est aussitôt fait sentir à la bourse, tous les fonds ont éprouvé une forte dépréciation. » Par ailleurs, le trône du roi n'avait pas été traîné dans les rues comme dans l'article de L'Avenir; au contraire, il « fut promené en triomphe, porté sur les épaules du peuple ». Par conséquent, la dynamique révolutionnaire était présentée différemment : la lutte était jugée en partie inutile, en partie malheureuse, quelque peu justifiée, mais surtout regrettable et futile.

Le rédacteur de La Minerve affirmait vouloir simplement donner aux événements "leur véritable couleur», sans passer de jugement sur la "légalité ou l'illégalité de la révolution française ». Manifestement, ces deux objectifs (interpréter la révolution et ne pas la juger) étaient incompatibles. La Minerve portait en fait un jugement subtil en mettant en intrigue la révolution comme un événement regrettable et en manifestant son mécontentement face à la violence populaire. «C'est après cette évacuation du château royal, que le peuple se livra aux scènes de désordre, dont nous avons eu la douleur de rendre compte ", se lamentait le rédacteur. La violence révolutionnaire que L'Avenir jugeait émancipatrice était considérée comme inutile par La Minerve. Le conservatisme politique de son rédacteur conduisit La Minerve à peindre la révolution en France sous des couleurs très sombres. 
Pour sa part, L'Avenir continua à proposer une mise en intrigue révolutionnaire émancipatrice en analysant le conflit en Irlande. Citant le journal The Nation de Dublin, le rédacteur de L'Avenir affirmait qu'une révolution semblait s'être produite en Irlande en 1848 . Il présentait une courte sélection d'événements correspondant étroitement à la mise en intrigue émancipatrice élaborée plus tôt pour la révolution en France :

Les orangistes, catholiques, enfin toute l'Irlande se serait levée comme un seul homme pour secouer le joug de la tyrannie anglaise. Le peuple aurait eu le dessus et un gouvernement provisoire aurait été nommé. «On porte, dit le Nation [sic], la cocarde orange et verte et aucune parole ne pourait [sic] exprimer la joie qui se manifeste dans notre capitale libre. ${ }^{41}$ "

Les trois étapes sont manifestement présentes : l'oppression, le point de rupture et la liberté se succédaient et donnaient lieu à un mouvement émancipateur. Cet article fut suivi d'informations complémentaires reçues par télégraphe de New York via Toronto. Elles contredisaient la première version des événements, précisant que les troupes gouvernementales avaient réprimé la révolte et tué deux cents Irlandais ${ }^{42}$. Cependant, L'Avenir, qui considérait que ces informations contredisaient complètement la mise en intrigue émancipatrice, les jugea "étouffées autant que possible par le télégraphe et encore plus par la presse anglaise de cette ville [Toronto] ${ }^{43}$. Manifestement, l'origine et la fiabilité des nouvelles étaient moins importantes que le sens qu'on pouvait projeter sur un événement. On donnait à des informations qui pouvaient facilement s'intégrer à la mise en intrigue émancipatrice la priorité sur des informations qui ne pouvaient pas l'être.

En outre, en décrivant la révolution allemande de mars 1848, le rédacteur de L'Avenir expliquait que les étudiants 
avaient mené une révolte populaire contre 20000 soldats à Berlin et n'avaient cessé que quand le roi eut, par une proclamation écrite, accepté toutes les exigences populaires. En même temps, L'Avenir portait un jugement subtil sur les événements : l'assentiment des Berlinois était «à coup sûr un exemple inoui [sic] de modération; en France on a dit : "il est trop tard" ", commentait le rédacteur ${ }^{44}$. La mise en intrigue de la révolution en France exigeait un point culminant violent marquant le transfert de la souveraineté aux masses - le moment où les masses ont dit : «Il est trop tard. »C'est ainsi que le rédacteur se montra perplexe devant l'insuffisance du zèle révolutionnaire et républicain des Allemands. Quand les masses révoltées furent sur le point d'obtenir l'entière souveraineté et l'autonomie gouvernementale, elles abandonnèrent les idéaux républicains et acceptèrent une concession inférieure, puisque le roi demeurait chef de l'État. Le subtil ton négatif découlait de la juxtaposition de l'exemple français et de l'exemple allemand "avorté ». Le fait de qualifier le dénouement abrupt d'« inoui [sic]» laissait entendre que la ligne de conduite adoptée par les Allemands était inattendue et presque incroyable. En d'autres termes, pour L'Avenir, tout ce qui était en deçà de la terrible proclamation «il est trop tard", du transfert de tout le pouvoir au peuple et de la destruction de la monarchie était inusité. C'est ainsi que le 8 avril 1848, L'Avenir appuya implicitement un type de républicanisme favorisant l'emploi de la violence révolutionnaire.

Dans l'atmosphère politique bas-canadienne d'après 1837, les couleurs républicaines et révolutionnaires de L'Avenir devaient être camouflées, puisque tout appel à une autre rébellion équivaudrait à un suicide politique. Pourtant, les articles de L'Avenir semblaient suggérer la forte éventualité de nouveaux actes de violence politique dans le Bas-Canada. Ayant déjà présenté à son public une mise en intrigue éman- 
cipatrice, L'Avenir donna subtilement des détails sur la situation bas-canadienne que les lecteurs pouvaient intégrer au schéma révolutionnaire global.

En Pologne, annonçait L'Avenir, les autorités russes avaient interdit la publication de nouvelles relatives à la révolution en France parce qu'elles craignaient que l'humeur révolutionnaire atteigne le point d'ébullition si les nouvelles de la révolution en France parvenaient aux oreilles des Polonais. L'Avenir osa demander : "Les journaux anglais de cette ville [Montréal] voudraient-ils en faire autant sur les nouvelles de la révolution d'Irlande $?^{45}{ }^{\star}$ Cela laissait entendre que la même dynamique existait dans le Bas-Canada, où, de l'avis des rouges, les nouvelles d'Irlande pouvaient donner un élan révolutionnaire à la population canadienne-française opprimée.

Le leitmotiv révolutionnaire refit également surface dans les discours de Papineau. Dans un discours au Marché Bonsecours de Montréal, discours qui fut publié dans L'Avenir, l'ancien leader patriote déclara que l'injustice du gouvernement canadien, lequel par le passé avait préféré discorde et pauvreté générales à une division équitable du pouvoir, devait être corrigée, et que pour ce faire le gouvernement devait remplir immédiatement toutes ses promesses ${ }^{46}$. «Qu'il [le gouvernement] se hâte de mettre d'accord la pratique avec les phrases, avertit Papineau, pour que les mots fatidiques, il est trop tard, ne deviennent pas vrais ${ }^{47}$. $) \mathrm{La}$ référence à la révolution en France était évidente : si le gouvernement en venait à agir comme son homologue français avant la révolution, la situation atteindrait un point de rupture et la violence éclaterait. Bien sûr, en dépit de leur ton révolutionnaire, Papineau et ses partisans de L'Avenir formulèrent leurs avertissements avec soin et n'en appelèrent jamais à la révolution dans le 
Bas-Canada. Ils se servirent simplement de l'exemple européen pour indiquer qu'une telle révolution était possible.

Dans son discours du 15 avril 1848, Papineau emprunta la mise en intrigue émancipatrice établie dans L'Avenir pour la révolution en France, l'élargit et souligna la probabilité d'une nouvelle révolution en Angleterre, ainsi que son effet potentiel sur le Bas-Canada :

La révolution française doit bouleverser le monde. Le peuple anglais, écrasé sous le double poids de son aristocratie laïque et religieuse fera, lui aussi peut-être, un effort. Cette conflagration générale pourra atteindre l'Angleterre; elle doit suivre ou précéder un mouvement révolutionnaire en Irlande : et ce qu'on peut attendre de plus probable, c'est une guerre entre l'Angleterre et quelque puissance continentale. Avec un trésor épuisé, pour peu qu'on demande avec énergie, l'Angleterre ne sera pas tentée de nous refuser cet acte de justice [...]. [L]e Bas-Canada [...] pourrait lui donner au besoin aide, protection contre les ennemis du dehors et du dedans ${ }^{48}$.

Avec cette déclaration, Papineau atteignit de nombreux objectifs politiques et rhétoriques. Premièrement, il indiquait que la violence extérieure pourrait modifier à terme la situation dans le Bas-Canada, mais il mit cette idée de l'avant avec prudence, laissant entendre que l'Europe serait le théâtre de violence et soulignant même que l'Angleterre pourrait compter sur le Bas-Canada à la suite d'une guerre en Europe, mais seulement si elle répondait aux demandes politiques des BasCanadiens. S'en prenant à l'Union dans ce même discours, Papineau expliquait que " [s]on maintien dépendrait de la volonté du maittre qui, lorsqu'il est fort, s'est toujours montré peu soucieux des justes réclamations des faibles ${ }^{49}$ ». En d'autres mots, la possibilité d'obtenir des réformes dépendait des rapports de force entre le gouvernement impérial et la colonie : 
la révolution potentielle affaiblirait la Grande-Bretagne et la colonie pourrait alors imposer dans une certaine mesure ses exigences réformistes. Troisièmement, Papineau présenta un ordre des événements où l'Angleterre pourrait encore survivre à l'assaut révolutionnaire et jouir du soutien d'au moins une de ses colonies. De cette manière, il se mettait à l'abri d'éventuelles accusations d'incitation à la révolution dans le Bas-Canada et à la guerre contre l'Angleterre. La mise en intrigue émancipatrice des événements se poursuivit jusqu’à sa conclusion, où paix et calme sont rétablis dans le cadre républicain : Papineau prévenait que l'heure de la révolution pouvait « sonner bientôt [et] le calme p[ourrai]t ensuite se rétablir pour longtems $[s i]^{50} \%$.

Mais au cours du mois de mai 1848, le zèle révolutionnaire des rouges allait se calmer. Dans son premier numéro de mai, le rédacteur de L'Avenir exprimait son inquiétude concernant « les mouvements extraordinaires qui se faisaient [sic] de la part du militaire. On transportait du canon et des munitions de l'Ile Ste-Hélène à la ville ; on parlait de sociétés secrètes $^{51}$. 》 Malgré les assurances positives données par lord Elgin à propos de ces mouvements militaires, le rédacteur de L'Avenir exprimait sa consternation face à cette situation. Il croyait - ou prétendait croire - que le " gouvernement militaire » agissait de concert avec les journaux conservateurs et visait L'Avenir par cet accroissement de la mobilisation militaire :

A Québec, on doubla les gardes, on remplit les arsenaux, on ravitailla leforts,son [sic] répara les brèches, on ferma les portes de la ville; à Montréal, on doubla, nous dit-on, aussi les gardes, on manda la cavalerie provinciale des frontières; tout le Bas-Canada, en un mot, s'est mis sur le qui vive! Honneur au Journal de Québec! Honneur à la Revue! Honneur aux Mélanges $^{52}$ ! 
En mentionnant les journaux ministériels, L'Avenir établissait en fait un lien entre l'escalade militaire et les idées prétendument tyranniques des conservateurs. Malgré son zèle révolutionnaire initial, la militarisation des deux principales villes du Bas-Canada refroidit passablement L'Avenir. Le journal commença alors à s'autocensurer et à tempérer la ferveur révolutionnaire qu'il avait manifestée depuis mars 1848.

\section{Vers un républicanisme modéré : l'abandon de la mise en intrigue émancipatrice en juillet 1848}

La contre-révolution en Europe et les attaques des ouvriers contre la République française ébranlèrent profondément la mise en intrigue émancipatrice telle qu'utilisée antérieurement par L'Avenir. Prenant acte des changements dans la politique française et européenne, L'Avenir commença à se montrer partisane d'un type de républicanisme modéré qu'il dissociait de la violence révolutionnaire et du républicanisme radical. En juin 1848, les classes françaises les plus défavorisées se sentirent trahies par le gouvernement provisoire, parce que leurs espoirs de changement et de meilleures conditions de vie avaient été ignorées par les politiciens qui ne se souciaient que de leur survie politique dans le Paris instable d'après la révolution. Les violences qui éclatèrent au cours du même mois furent en grande partie provoquées par des ouvriers parisiens qui se sentaient abandonnés ${ }^{33}$. "Les nouvelles que ce steamer [le Britannia] nous apporte, commentait le rédacteur de L'Avenir relativement aux nouvelles de France, ne sont pas aussi rassurantes que nous l'espérions ${ }^{54}$. » Le 12 juillet, des nouvelles des combats se déroulant à Paris et opposant Cavaignac aux républicains radicaux parvinrent dans le Bas-Canada et l'opinion de L'Avenir commença à évoluer pour devenir défavorable aux révoltes populaires, celui-ci soulignant que «le nombre des victimes avait atteint un chiffre effrayant ${ }^{55} \%$. 
Cette nouvelle attitude était là pour durer. Tout en rapportant les événements des journées de Juillet, L'Avenir choisit dans La Revue des Deux Mondes ${ }^{56}$ un article qui présentait une mise en intrigue défavorable aux ouvriers parisiens révoltés. Le tout premier paragraphe donnait le ton de l'article: "L'un des drames les plus sanglans [sic] dont le monde ait été témoin, l'une des insurrections les plus obstinées qui aient ensanglanté l'histoire de France depuis son origine, vient d'avoir lieu à Paris ${ }^{57}$. » Cet article, contrairement au compte rendu antérieur, décrivait les révoltés comme de violents insurgés et n'examinait pas sérieusement les causes de leur colère ${ }^{58}$. Selon cet article, les violences éclatèrent après qu'un groupe d'ouvriers fut allé porter plainte devant le maire de Paris, Armand Marrast ${ }^{59}$. Ce dernier n'était toutefois pas prêt à écouter leur chef à cause de sa participation à la tentative d'instauration d'un gouvernement révolutionnaire le $15 \mathrm{mai}^{60}$. Peu après, les insurgés érigèrent des barricades et lorsque la situation fut devenue explosive, le gouvernement donna au général Cavaignac pleins pouvoirs pour restaurer l'ordre. Il essaya d'abord d'offrir l'amnistie aux insurgés, qui refusèrent obstinément. Le compte rendu indiquait également que les insurgés étaient des républicains radicaux qui brandissaient «le drapeau rouge, avec le moto république démocratique et sociale $^{61} »$. Il concluait en rapportant que de nombreux généraux français étaient morts au cours des combats et que les insurgés avaient finalement été écrasés ${ }^{62}$.

Comme en témoigne le compte rendu cité, L'Avenir a choisi de réimprimer une version des événements défavorable aux républicains radicaux. Par conséquent, au milieu du mois de juillet 1848, la mise en intrigue émancipatrice initiale de L'Avenir fut remplacée par une mise en intrigue mettant l'accent sur la futilité et l'illégitimité de la lutte violente des républicains radicaux. "Les journaux américains arrivés par 
la malle d'hier nous en fournissent d'une manière à ne plus douter de l'horrible carnage qui a signalé les journées du 23, 24 , et du 25 juin dernier ${ }^{63}$ ", écrivait le rédacteur. La situation était renversée : contrairement à la glorieuse révolution de février, qui dura également trois jours, les journées de Juin, en tant que symboles d'un républicanisme radical et violent, étaient une abomination aux yeux du rédacteur.

Néanmoins, L'Avenir continua de se faire l'avocat d'un républicanisme modéré (incarné par la révolution de février) pendant tout l'été 1848. Par exemple, le rédacteur loua la Charte républicaine française, "une œuvre [...] capitale », et il espérait que ses auteurs demeurent «fidèles aux principes de la révolution et qu'ils proposent une constitution essentiellement démocratique où tout repose sur le suffrage direct et universel ${ }^{64} \gg$. Ces expressions d'inquiétude et d'admiration indiquent avec quelle hardiesse L'Avenir était maintenant prêt à proclamer sa sympathie pour une forme modérée de républicanisme. À la suite d'un article positif sur L'Avenir paru dans le journal parisien La Ruche populaire, le rédacteur de L'Avenir exprima le désir que s'établissent des liens d'amitié et « de fraternité » entre la France et le Bas-Canada. " Cette amitié, poursuivait le rédacteur, nous ne la recherchions ni dans la famille de nos anciens maîtres, ni sur les degrés [sic] d'un nouveau trône, ni dans la popularité d'un grand nom ; mais dans la classe où naissent toutes les idées généreuses, où se forment tous les projets sublimes...d'où est enfin sortie la république de $48 !^{65}$ »Par conséquent, le lien véritable unissant les rouges et leurs homologues français, dont la description était très vague, était le lien républicain, les autres similitudes étant considérées comme superficielles.

L'Avenir voyait deux causes à tous les maux dont souffraient les Canadiens français : l'Acte d'Union et le gouvernement responsable. Paradoxalement, le gouvernement respon- 
sable, qui donnait plus de pouvoir politique aux leaders canadiens-français, causa davantage de problèmes aux rouges parce qu'il enlevait à leurs compatriotes l'envie d'exiger la totalité de leurs droits politiques, entre autres l'autonomie gouvernementale populaire, qui était le plus important. Dans un pareil contexte, les républicains canadiens-français se sentirent obligés d'exposer les véritables idées républicaines et d'affirmer la possibilité de leur mise en pratique dans le Bas-Canada. Dans un discours prononcé au cours d'une réunion à Yamachiche en juillet 1848, Dessaulles établit le lien suivant entre la façon dont les républicains concevaient la souveraineté populaire et le gouvernement responsable : «Qui dit responsabilité au peuple dit souveraineté du peuple. Or, quand nos amis qui veulent sincèrement nous servir, quand nos ministères nous disent: "Vous n'obtiendrez peut-être pas justice" ils nous disent implicitement: "Vous n'avez pas le gouvernement responsable." ${ }^{66}$ " Dans le contexte du commentaire de Dessaules, " obtenir justice » concernait le désir de se débarrasser tant de l'Acte d'Union que du gouvernement responsable. Par conséquent, selon l'idéal républicain concernant un gouvernement autonome populaire, les Canadiens français vivaient dans l'illusion de la souveraineté populaire parce que les pouvoirs des ministres étaient limités par l'Angleterre et qu'ils n'osaient pas présenter d'exigences radicales. Dans ce cas, «ils admettent que le gouvernement responsable est une duperie », écrit Dessaules ${ }^{67}$.

Entre le 30 septembre et le 2 octobre 1848, le rédacteur de L'Avenir revint sur le sujet de l'efficacité du système de gouvernement républicain et sur les graves lacunes du gouvernement du Bas-Canada. D’abord, il décrivit la manière opportune avec laquelle la République française gérait une petite crise causée par la classe ouvrière parisienne mécontente : le gouvernement s'empressa d'allouer de l'argent aux 
industries qui avaient besoin d'aide afin de calmer et de mầtriser l'agitation potentielle des ouvriers ${ }^{68}$. "La République, concluait le rédacteur, qui est le gouvernement de tous pour tous, se montrera moins oublieuse des besoins et des droits populaires. Là sera sa mission, là sera son salut ${ }^{69}$. » À l'opposé, les ministres du Bas-Canada étaient critiqués pour leur incapacité à contribuer valablement à la vie politique du BasCanada : «Le mérite des ministres, soulignait le rédacteur, ne git pas dans le nombre de leurs actes législatifs, mais dans la viabilité et solidité de ces actes ${ }^{70}$. » Donnant un exemple où le gouvernement avait manqué de "viabilité et [de] solidité », le rédacteur de L'Avenir critiquait la proposition ministérielle de modifier le système électoral en accroissant le nombre de députés élus, mais sans changer la proportion des sièges auxquels avaient droit le Haut et le Bas-Canada. Il expliquait qu'une pareille réforme ne corrigerait que «quelques abus minimes dont la réparation ne devrait pas être définie réforme électorale par rapport au Bas-Canada ${ }^{71} »$. La différence était maintenant évidente : la France était une république et elle fonctionnait bien parce que les gens étaient convenablement représentés au sein du gouvernement. Ce n'était pas le cas au Bas-Canada et il en pâtissait. L'Avenir ne se contenta pas de critiquer le gouvernement, mais il s'efforça également d'imposer son point de vue républicain aux autres journaux canadiens-français.

À la fin des années 1840, le discours de L'Avenir reflétait étroitement ce que Per Mouritsen décrivait comme le type dominant de républicanisme : la version populiste démocrate. Ce type de républicanisme «inventa [...] le peuple en tant que corps uni de détenteurs de droits (naturels) capable de se gouverner lui-même en fonction de ses intérêts propres ${ }^{72} »$. Les partisans du républicanisme populiste démocrate présumaient que les gens s'entendaient nécessairement sur ce que leurs 
droits devaient être. De plus, l'espace civique était organisé en termes d'honneur et de honte : instaurer la vigilance civique sous-entendait dévoiler des complots secrets contre la collectivité et dénoncer ceux qui ne discernaient pas où se trouvait le bien commun ou qui, de quelque façon que ce soit, refusaient de promouvoir ce bien ${ }^{73}$. De plus, le meilleur gouvernement était celui qui était étroitement contrôlé par ceux qu'il gouvernait au sein d'une république petite et homogène ${ }^{74}$.

L'Aveniradopta un point de vue républicain de tendance populiste démocrate lorsqu'il critiqua l'hésitation de $\mathrm{La} \mathrm{Mi-}$ nerve à soutenir une réforme électorale qui aurait intégré le principe de représentation en fonction de la population. Celleci aurait attribué les sièges au sein de l'Assemblée en proportion du nombre d'habitants dans le Haut et le Bas-Canada, ce qui était davantage conforme à l'idéal populiste démocrate d'un gouvernement reflétant étroitement les opinions de ceux qu'il gouverne. L'Avenir résumait ainsi la position de son rival: "La Minerve nous dit qu'elle n'a pas d'objection à demander cette réforme basée sur la population, s'il est possible de l'avoir telle, et si elle doit nous être avantageuse. Voila [sic] une curieuse manière de se tirer d'affaire, et de donner une réponse $^{75}$. » Ainsi, deux aspects du point de vue de La Minerve irritaient le rédacteur de L'Avenir: d'abord les doutes qu'il semblait entretenir sur les avantages de la représentation proportionnelle, et ensuite sa réticence à prendre vigoureusement position sur des sujets d'une importance cruciale pour les intérêts collectifs des Canadiens français.

De plus, dans un article abordant le sujet des différents modes d'opposition au sein du gouvernement, L'Avenir expliquait en quoi son point de vue différait de celui des journaux ministériels. Encore une fois la pomme de discorde était la souveraineté populaire. «Appuyez-vous sur le peuple, deman- 
dait instamment L'Avenir aux ministres, lui seul est inébranlable. Non! Non, répondent les quatre poteaux du ministère. Taisez-vous, vous êtes dans l'opposition, vous n'êtes pas avec nous ${ }^{76}$. » Poussant encore plus loin l'argumentation, le rédacteur affirmait que les rouges appartiennent « au parti libéral comme Canadiens et nous ne voulons pas qu'il agisse comme le ferait un parti tory ${ }^{77} \gg$. Puis il utilisait l'idée républicaine de l'autonomie gouvernementale populaire pour dénoncer le type de "parasites » tories qui éloigne le Parti libéral de ses véritables objectifs : "Si ces parasites cherchent à égarer l'opinion publique, nous travaillerons à ouvrir les yeux au peuple afin qu'il guide le ministère, car c'est au peuple à commander ${ }^{78}$. » En d'autres mots, L'Avenir, malgré son identification rhétorique au parti libéral, était l'organe républicain exerçant une vigilance civique et mettant en garde contre les éléments " parasites » antirépublicains qui voulaient maintenir la corruption au sein du gouvernement en l'empêchant d'adopter la représentation proportionnelle.

L'analyse que fit L'Avenir de l'indifférence manifestée par Le Journal de Québec envers la forme de gouvernement du Bas-Canada constitue un autre exemple de vigilance civique. "Que nous importe, à nous, que nous vivions sous une monarchie constitutionnelle ou sous une démocratie pure, écrivait L'Avenir citant Le Journal de Québec, pourvî [sic] que le peuple soit heureux et content, et qu'il jouisse d'une douce et paisible liberté ${ }^{79}$. " En d'autres termes, tant que personne ne contraignait les gens, tout allait bien. L'Avenir critiquait cette façon de voir en soulignant que toutes les nations recherchent l'ordre social parfait et que Le Journal avait tort de se contenter d'une monarchie constitutionnelle ${ }^{80}$. Selon L'Avenir, il aurait dû comparer « la monarchie constitutionnelle et le gouvernement démocratique » afin de choisir la meilleure option. 
Le rédacteur ne précisait pas en quoi consisterait cette meilleure option sinon que ce serait « une démocratie pure ${ }^{81}$ ».

Ce qui était en train de se produire était évident : l'article, reprenant les arguments développés au cours des mois précédents, présentait encore la république comme la forme parfaite de gouvernement. Par exemple, le rédacteur affirmait que « le bonheur d'un peuple comme celui des individus n'est que relatif. A mesure que ses institutions sociales se perfectionnent, la somme de son bonheur augmente ${ }^{82}$. » Ainsi, pour reprendre l'idée d'Isaiah Berlin, le rédacteur de L'Avenir ne défendait pas la conception libérale de la liberté, qui repose sur l'absence d'ingérence dans la vie d'un individu (freedom from $)^{83}$. Il promouvait plutôt une amélioration des institutions gouvernementales considérée bénéfique à l'ensemble de la collectivité. Dans un échange antérieur avec Le Journal de Québec, L'Avenir affirmait ainsi que c'est «le peuple et non pas le ministère qui est le souverain ${ }^{84} »$. Ainsi, l'objectif réformiste ne pouvait être atteint qu'une fois la souveraineté populaire établie et la liberté républicaine intégrée aux institutions gouvernementales. L'Avenir continuait de soutenir subtilement qu'il fallait que le Bas-Canada devienne une république.

\section{Les rouges : des républicains modérés prêchant une révolution pacifique}

Le 16 août 1848, L'Avenir publiait une lettre enthousiaste sur le chartisme en Angleterre ${ }^{85}$. L'auteur prédisait que " [c]e pays [l'Angleterre] va éprouver une révolution fondamentale dans son gouvernement, sans qu'il en coûte une seule goutte de sang ${ }^{86} \gg$. Dans la foulée de cette révolution, l'Angleterre allait se déclarer "sinon républicaine, au moins très rapprochée de cet état ${ }^{87}$ \%. Avec ce document, et après avoir abandonné la mise en intrigue émancipatrice, L'Avenir com- 
mença à peindre le mouvement révolutionnaire sous des couleurs différentes. Maintenant, la révolution se ferait par le passage tout à fait pacifique d'une monarchie constitutionnelle à un gouvernement républicain. Peu après avoir fait cette distinction, L'Avenir reliait la révolution sans effusion de sang au contexte bas-canadien.

L'Avenir apporta les précisions suivantes sur les différences entre deux types de révolution: "Parmi les peuples, les uns vont plus vite, les autres plus lentement, quelquefois ils alternent; les uns renversent et brisent violemment les obstacles : telle est la glorieuse patrie de nos ancêtres; les autres au lieu de les briser, les détournent: telle est notre métropole $^{88}$. » La révolution en France et ses principes constituaient toujours une façon exemplaire d'imposer le républicanisme, mais elle avait perdu de sa pertinence pour le Bas-Canada parce que la structure de la colonie avait maintenant changé. Par conséquent, on n'avait pas besoin d'« une révolution matérielle et physique, mais bien d'une révolution purement morale et dans les idées ${ }^{89}$ ». Ainsi, en septembre 1848, L'Avenir avait véritablement changé de point de vue sur la possibilité d'une révolution dans le Bas-Canada. Il préférait maintenant une révolution non violente et le passage pacifique d'une monarchie constitutionnelle à une république, abandonnant le langage violent du début de l'année 1848 lorsque L'Avenir annonçait qu'une révolution violente allait vraisemblablement éclater si aucune concession politique n'était accordée aux Canadiens français ${ }^{90}$. Cette fois encore les événements en France eurent un impact sur le revirement idéologique de L'Avenir. Réalisant que la confrontation des politiciens républicains et des promonarchistes radicaux devenait de plus en plus explosive, L'Avenir conclut que seul un républicanisme modéré pouvait assurer un avenir stable à la France. 
La première menace à laquelle la République française fut confrontée vint des tendances monarchistes de LouisNapoléon Bonaparte. L'Avenir reproduisit un article du journal Le Courrier des États-Unis, dont le correspondant, Frédéric Gaillardet, affirmait que Louis-Napoléon faisait seulement semblant d'être républicain parce qu'il avait encouragé à ses propres fins l'adoption d'un projet de loi constitutionnelle stipulant que le peuple français devait élire le prochain président $^{91}$. «Une fois élu, mettait en garde le correspondant, le prince confisquerait peu à peu la République à son profit, en faisant décréter la présidence à vie, puis héréditaire, tout comme a fait son oncle, d'impériale mémoire ${ }^{92}$. » À la mi-novembre 1848, le rédacteur de L'Avenir, reprenant l'opinion de Gaillardet, exprimait ses craintes sur l'émergence de tendances antirépublicaines que représentait Louis-Napoléon. Il citait un article qui mettait en garde contre l'abandon des valeurs républicaines sous la férule de Louis-Napoléon : «Une République doit être franche, loyale et vraie en tout; si elle manquait à ces conditions, elle ne deviendrait pas populaire, et elle périrait un jour aussi misérablement que les royautés ${ }^{93}$. " La publication en novembre d'articles successifs considérant avec scepticisme l'attachement de Louis-Napoléon à la république témoignait du malaise de L'Avenir face au paradoxe que constituait un président républicain ayant des sympathies monarchistes.

La seconde menace qui pesait sur la France était le fait d'éléments républicains radicaux. Lorsque la nouvelle de l'élection de Louis-Napoléon à la présidence fut connue, le rédacteur de L'Avenir présenta sobrement les résultats du vote et cita un article du journal français antimonarchiste Le Siècle $e^{94}$ pour expliquer la dynamique du vote. Ce dernier déplorait que les partisans de Louis-Napoléon aient principalement été dés anarchistes radicaux et des socialistes démocrates dont 
l'objectif principal était la défaite du général Cavaignac ${ }^{95}$. L'Avenir citait également La Démocratie pacifique, un journal républicain qui adhérait aux opinions socialistes de Charles Fourier ${ }^{96}$, la considérant comme « bien placée pour savoir comment ont voté les démocrates socialistes, et les motifs qui ont déterminé leurs votes ${ }^{97} \%$. Le thème des renégats refaisait surface : La Démocratie pacifique attribuait la victoire de LouisNapoléon aux républicains radicaux qui avaient abandonné Alexandre Ledru Rollin et François-Vincent Raspail afin d'assurer l'échec du général Cavaignac ${ }^{98}$. Dans ces articles, deux éléments menaçaient le bien-être de la république. On mettait l'accent sur le système républicain mis à mal par LouisNapoléon, mais à d'autres moments on insistait sur les agissements des républicains radicaux, qu'ils se révoltent contre les républicains modérés ou qu'ils soutiennent ce qui était perçu comme les tendances monarchistes de Louis-Napoléon.

En même temps que le journal présentait cette dynamique politique, l'idéologie républicaine de L'Avenir commença à se stabiliser au fur et à mesure qu'il prenait graduellement position à l'égard des éléments promonarchistes et républicains radicaux en France. Par exemple, lorsqu'il commença à analyser les actes de Louis-Napoléon, L'Avenir souligna que "[à] peine formé, le ministère a subi une modification, sans grande portée en elle-même, mais qui a décelé, dès l'abord, de graves dissentiments entre le chef du pouvoir exécutif et son cabinet ${ }^{99} »$. Fait plus fondamental, les nouveaux problèmes politiques menaçaient d'ébranler ce qui était, pour L'Avenir, l'élément stabilisateur de la république : les républicains modérés. «Les modérés qui lui [Louis-Napoléon] conservent encore un respect sincère, voient dans la prolongation de sa carrière des dangers réels et lui conseillent de ne point s'obstiner à rester trop longtemps ", notait le rédacteur de L'Ave$n i r^{100}$. 
À ce moment-là, la situation en France était pratiquement revenue à son point de départ. Un président aux tendances monarchistes avait pris le contrôle du gouvernement par l'intermédiaire d'un système républicain qui avait été mis en place pour remplacer la précédente monarchie évincée. L'Avenir y voyait un grand danger. Alors que la république venait tout juste de survivre à l'attaque violente des républicains "rouges", ceux-ci jouaient un rôle dans l'apparition d'une autre crise qui mettait encore une fois en péril la survie du gouvernement républicain modéré en France. Dans tous les articles sur les événements entourant la présidence de Louis-Napoléon, L'Avenir s'efforçait de prendre le parti des républicains modérés et de se dissocier des républicains radicaux, dont les méthodes s'étaient avérées préjudiciables à la cause républicaine en France.

Comme cela avait été le cas précédemment, les idées apparues lors de l'examen des affaires françaises trouvèrent rapidement un écho dans le contexte bas-canadien. Dès le 18 octobre 1848, L'Avenir relevait le fait que Le Journal de Québec avait accusé les rouges d'être des "républicains rouges ${ }^{101}$ ». Avant de répondre officiellement à cette accusation, L'Avenir demandait une explication de ce qu'on avait voulu dire par ce terme. Dans l'intervalle, il continuait de donner des indications de ses sympathies réelles et de sa tendance idéologique. Par exemple, il se moquait des peurs exprimées dans Les Mélanges religieux, allant jusqu'à prétendre que les rédacteurs de ce périodique croyaient que "[e]ncore six mois et il sera trop tard, la constitution aura disparu, avec elle la monarchie, avec elle notre église, avec elle nos pontifes, avec elle nos prêtres, avec elle la propriété, la famille, la société et la patrie, tout en un mot excepté ces enragés Rouges qui dévasteront le pays ${ }^{102}$ ». Le rédacteur de L'Avenir, poursuivant sur le même ton railleur, expliquait que Les Mélanges religieux retardait très efficacement 
l'instauration présente ou future d'une république dans le BasCanada par ses comptes rendus de naissances, de décès, de mariages, de promenades et d'autres nouvelles des familles royales européennes ${ }^{103}$. Cette réponse sous-entendait que seule l'idéologie républicaine convenait aux Canadiens français.

Au cours des mois suivants, L'Avenir exprima son point de vue sur le lien entre républicanisme et révolution en termes plus explicites. Dans les jours entourant le premier anniversaire de la révolution de février, le rédacteur de L'Avenir publia des commentaires révélateurs sur les événements de l'année précédente en Europe et dans le Bas-Canada. D'un ton louangeur, il exprima son enthousiasme pour la naissance de la République française : "Il y a aujourd'hui un an, jour pour jour, qu'une clameur immense et solennelle faisait retentir dans Paris le glas funèbre de la royauté, en même temps que le baptême régénérateur d'une démocratie qui inaugurait pour la vieille Gaule une nouvelle vie politique ${ }^{104}$. » Puis il. citait les exemples de révolutionnaires et de rebelles italiens, allemands et irlandais qui aspiraient à copier l'exemple français $^{105}$. Sa seule crainte pour l'Europe était qu'on en revienne au statu quo d'avant la révolution ${ }^{106}$.

Néanmoins, le rédacteur de L'Avenir exprimait son désenchantement face aụx luttes révolutionnaires qui se poursuivaient dans l'ensemble de l'Europe au début de 1849. « En Italie comme en Allemagne, faisait-il observer, il continue à régner une sorte d'anarchie paisible, qui n'est à proprement parler ni l'état de révolution, ni le fonctionnement des institutions régulières ${ }^{107}$. » L'incapacité des peuples européens à instaurer des gouvernements républicains irritait L'Avenir, pour qui les révolutionnaires oscillaient perpétuellement entre un passé monarchique insatisfaisant et un futur républicain prometteur, incapables de s'engager avec assurance dans l'une ou l'autre voie ${ }^{108}$. «L'Europe est grandement bouleversée par 
l'élément révolutionnaire, faisait-il observer en novembre 1848, mais cela durera-t-il longtems [sic] ? $^{109}$ "

Puis, tournant ses regards vers le Bas-Canada, L'Avenir clarifiait la position des rouges en ce qui a trait au lien entre républicanisme et révolution : " [N]ous n'entendons pas faire du prosélytisme républicain comme nos absolutistes, nous allons dire comme nos légitimistes canadiens ont cru devoir nous en accuser. Tout en saluant avec joie le règne du peuple en Europe, nous ne prétendons pas prêcher ici des idées révolutionnaires, dans le sens qu'on veut donner au mot de révolution ${ }^{110}$. » L'utilisation du terme " prosélytisme républicain » a besoin d'être expliquée dans ce cas-ci. D'abord, les deux phrases ci-dessus établissaient un lien direct entre le prosélytisme républicain agressif et la violence révolutionnaire. Comme nous l'avons déjà expliqué, L'Avenir rejeta l'insistance du républicanisme radical à utiliser des moyens violents pour atteindre ses objectifs à la fin de 1848 parce qu'il les considérait inefficaces. Par conséquent, c'est du républicanisme radical violent que cherchait à se dissocier le journal lorsqu'il refusa de s'adonner au prosélytisme républicain.

Au même moment, la tendance de L'Avenir à considérer d'un œil favorable l'idéologie républicaine modérée s'accentua progressivement. Cela est avéré par sa description des progrès institutionnels dans le Bas-Canada. Après avoir rejeté ce qu'il considérait comme un programme républicain radical de luttes incessantes, L'Avenir assurait à ses lecteurs qu'il ne croyait pas en une révolution violente dans le BasCanada : «Loin de nous, loin de nos compatriotes, toute idée d'anarchie, toute velléité de violence ${ }^{111}$. » Au lieu de luttes armées, insistait L'Avenir, le Bas-Canada allait connaitre des progrès naturels et non violents dans les domaines politique, commercial et industriel ${ }^{112}$. 
Deux semaines seulement avant son numéro du 24 février 1849, L'Avenir affirmait clairement qu'il croyait que le républicanisme modéré était voué à devenir l'idéologie dominante dans le Bas-Canada. Son rédacteur avait recours à l'analogie suivante pour défendre vigoureusement le concept républicain de la liberté populaire : «Vous pouvez tordre le fer des baïonnettes républicaines; mais vous ne pourrez jamais dessécher le germe de la liberté ; vous ne le pourrez pas, car sa sève lui vient du peuple, ce principe inépuisable et toujours fécond de tout ce qui se traduit par le mot progrès ${ }^{113}$. En fait, L'Avenir déclarait par là ouvertement et publiquement son adhésion à une idéologie de tendance républicaine. Et maintenant qu'il avait totalement dissocié républicanisme modéré et violence révolutionnaire, il pouvait avec assurance exprimer son désir de voir instaurer un système républicain modéré dans le Bas-Canada. "Et si, en nous rappelant le 24 février 1848, nous désirons voir s'ouvrir devant notre patrie un horizon plus pur et plus brillant; nous croyons en même temps que ce changement dans nos institutions devra s'opérer sans secousses aucunes", espérait le rédacteur ${ }^{114}$. Voilà qui témoignait de la maturité idéologique atteinte par L'Avenir. Il exprimait avec assurance son idéologie d'un républicanisme modéré, en juxtaposant la révolution française de 1848 et le progrès politique possible dans le Bas-Canada, ainsi que son espoir que, grâce à l'intégration des idées républicaines progressistes dans les institutions du Bas-Canada, un avenir plus radieux s'ouvre aux Canadiens français.

\section{$* * *$}

À sa naissance, L'Avenir n'avait pas adopté une position radicale sur les questions politiques. Cependant, LouisAntoine Dessaulles s'engageant toujours davantage dans la vie du journal, L'Avenir commença à promouvoir une vision 
républicaine de la situation politique dans le Bas-Canada. Cette perspective fut d'abord élaborée au cours de l'examen de la situation en Europe, décrite par L'Avenir sous la forme de mouvements émancipateurs. Alors que l'élan révolutionnaire en Europe s'intensifiait tout au long de l'année 1848, L'Avenir poursuivait avec plus d'assurance dans la voie du républicanisme dans laquelle il venait de s'engager, et laissait même entendre que les révolutions en Europe pourraient avoir un écho au Bas-Canada. Les rouges exprimèrent leurs opinions républicaines localement en utilisant des critères républicains pour juger des affaires politiques, notamment le devoir civique, la vigilance civique, l'autonomie gouvernementale populaire et l'opposition à la corruption politique.

Cette adhésion au républicanisme, d'abord plutôt vague, fut mieux définie par L'Avenir dans la deuxième moitié de 1848. Ayant observé les luttes opposant républicains radicaux et modérés en France au cours des journées de Juillet, L'Avenir voyait dans les radicaux un élément perturbateur et en vint graduellement à mettre de l'avant des arguments en faveur d'un républicanisme modéré. À la même époque, les rouges renoncèrent totalement à la violence et exigèrent l'instauration pacifique d'un républicanisme modéré dans le BasCanada. À la lumière de ces développements, il devient évident que le fait que les rouges se sont occasionnellement désignés eux-mêmes comme libéraux ne doit pas nous berner. Ils n'utilisèrent cette étiquette que comme un camouflage, pour rendre leurs opinions républicaines plus acceptables à la majorité des Canadiens français, qui allaient rapidement associer républicanisme et violence.

L'évolution idéologique déjà évoquée chez les rouges encourage les historiens à revisiter l'expérience du Bas-Canada à la fin des années 1840. Premièrement, le contexte européen fut un facteur important dans l'évolution des idéologies 
dans le Bas-Canada à la fin des années 1840. Les événements révolutionnaires étaient interprétés avec passion et l'évolution de la situation en Europe obligeait constamment les BasCanadiens à modifier ou justifier leurs positions idéologiques. Un examen de l'influence plus étendue de cette dynamique au sein des autres groupes politiques canadiens-anglais et canadiens-français pourrait donner des résultats prometteurs. Deuxièmement, cette étude montre également l'importance du républicanisme dans le Bas-Canada après 1837. Une analyse de la manière dont d'autres idéologies interprétèrent la révolution européenne de 1848 pourrait démontrer une présence plus importante qu'on l'a estimée des thèmes et des valeurs républicains au Bas-Canada à la fin des années 1848 et permettre de mieux comprendre le conservatisme et l'ultramontanisme en montrant comment ces idéologies ont été définies contre le républicanisme.

Traduction : Musée canadien des civilisations (Christian Bérubé)

\section{NOTES}

' Nous voulons remercier Michel Ducharme et Allan Smith pour leur appui constant, leur encouragement et les idées dont ils nous ont fait part au cours de la rédaction de cet article. Nous tenons également à remercier Robert Brain et les évaluateurs anonymes pour leurs judicieux conseils.

${ }^{2}$ La Nouvelle-Écosse a été la première à bénéficier d'une telle réforme en 1847.

${ }^{3}$ J. M. S. Careless, The Union of Canadas: The Growth of Canadian Institutions, 1841-1857, Toronto, McClelland and Stewart, 1967, p. 115.

${ }^{4}$ Pour une analyse du rôle de La Fontaine dans les années 1840, voir Jacques Monet, The Last Cannon Shot: A Study of French-Canadian Nationalism, 18371850, Toronto, University of Toronto Press, 1969.

${ }^{5}$ Après l'Union, le Bas-Canada a été légalement connu sous le nom de Canada-Est, et le Haut-Canada sous celui de Canada-Ouest. Toutefois, dans le 
présent article, les termes Bas et Haut-Canada seront utilisés pour décrire les deux parties de la nouvelle colonie.

' Jean-Paul Bernard, Les Rouges : libéralisme, nationalisme, et anticléricalisme au milieu du XIX' siècle, Montréal, Les Presses de l'Université du Québec, 1971, p. 35.

${ }^{7}$ Bernard, Les Rouges, p. 56-57.

${ }^{8}$ Fernande Roy, Histoire des idéologies au Québec aux XIXe et XX' siècles, Montréal, Boréal, 1993, p. 40.

"Yvan Lamonde, Histoire sociale des idées au Québec, 1760-1896, vol. 1, Québec, Fides, 2000, p. 293.

"' Ibid., 298-300.

"Yvan Lamonde, Louis-Antoine Dessaulles, 1818-1895 : un seigneur libéral et anticlérical, Saint-Laurent, Fides, 1994.

${ }^{12}$ Bernard Bailyn, Atlantic History: Concepts and Contours, Cambridge, Harvard University Press, 2005, p. 3.

${ }^{13}$ Voir Bernard Bailyn, The Ideological Origins of the American Revolution, Cambridge, Harvard University Press, 1967 ; Gordon S. Wood, The Creation of the American Republic, 1776-1787, Chapel Hill, University of North Carolina Press, 1969 ; J. G. A. Pocock, The Machiavellian Moment: Florentine Political Thought and the Atlantic Republican Tradition, Princeton, Princeton University Press, 2003 (1975).

${ }^{14}$ Pour l'utilisation du cadre atlantique, voir par exemple Jean-Pierre Wallot, "Révolution et réformisme dans le Bas-Canada (1773-1815) », Annales historiques de la Révolution française, 45, n" 213, 1973, p. 344-406 ; Wallot, "Frontière ou fragment du système atlantique : Des idées étrangères dans l'identité bascanadienne au début du XIX siècle ", Communications historiques de la Société bistorique du Canada (1983), p. 3-29. Pour une interprétation républicaine des rébellions de 1837, voir Louis-Georges Harvey, Le Printemps de l'Amérique française: Américanité, anticolonialisme et républicanisme dans le discours politique québécois, 1805-1837, Montréal, Boréal, 2005 ; Allan Greer, The Patriots and the People: The Rebellion of 1837 in Rural Lower Canada, Toronto, University of Toronto Press, 1993 ; Stéphane Kelly, La petite loterie. Comment la couronne a obtenu la collaboration du Canada frangais après 1837, Montréal, Boréal, 1997 ; Michel Ducharme, Aux fondements de l'État canadien : La liberté au Canada de 1776 à 1841, thèse de Ph.D. (histoire), Université McGill, 2005.

${ }^{15}$ Kelly, La petite loterie, 108. 
${ }^{16}$ L'influence de la théorie de la mise en intrigue de White sur la méthode employée dans le présent article est reconnue parce que notre analyse suit de près son cadre méthodologique général : les points d'accentuation textuelle sont dévoilés, puis reliés afin de trouver un trope, et enfin le trope est relié à une idéologie spécifique. Voir Hayden White, Metahistory: The Historical Imagination in Nineteenth-Century Europe, Baltimore, The Johns Hopkins University Press, 1975 (1973) ; Hayden White, The Content and the Form: Narrative Discourse and Historical Representation, Baltimore, The Johns Hopkins University Press, 1990 (1987).

${ }^{17} \mathrm{La}$ seule autre étude examinant comment les rouges percevaient les révolutions européennes de 1848 se trouve dans Rodrigue Samuel, L'image de la Révolution française de 1848 dans la presse du Canada français, (mémoire de mầtrise [histoire], Université Laval, 1978). Cependant, Samuel n'a analysé que les articles sur la révolution française de 1848 et a eu recours à une méthode quantitative empêchant d'évaluer adéquatement les implications idéologiques des articles. Or trouve une autre étude dont la méthode est proche dans une certaine mesure de la nôtre, mais qui ne traite pas des révolutions européennes de 1848, s'attachant avant tout à la littérature : Joseph Costisella, L'esprit révolutionnaire dans la littérature canadienne-française de 1837 à la fin du $X I X^{e}$ siècle, Montréal, Librairie Beauchemin, 1968.

${ }^{18}$ Bernard, Les Rouges, p. 33.

19 André Beaulieu et Jean Hamelin, La presse québécoise : des origines à nos jours, vol. 1, Québec, Les Presses de l'Université Laval, 1973, p. 157.

${ }^{211}$ Bernard, Les Rouges, p. 34.

${ }^{21}$ Dessaulles a écrit sous les pseudonymes Union et Campagnard (Beaulieu et Hamelin, La Presse québécoise, p. 158), ainsi que Anti-Union (Yvan Lamonde, dir., Louis-Antoine Dessaulles : Écrits, Montréal, Les Presses de l'Université de Montréal, 1994, p. 87).

${ }_{22}$ «L'Union », L'Avenir, 5 février 1848, p. 1, col. 1.

${ }^{23} \mathrm{Ibid}$.

${ }^{24}$ Campagnard, "Correspondance », L'Avenir (feuille supplémentaire), 26 février 1848, p. 2, col. 1.

${ }^{25}$ Quentin Skinner, «The Republican Ideal of Political Liberty », dans Gisela Bock, Quentin Skinner et Maurizio Viroli, dir., Macbiavelli and Republicanism, Cambridge, Cambridge University Press, 1990, p. 294-305.

${ }^{26}$ Skinner, «The Republican Ideal of Political Liberty », p. 301-302. 
${ }^{27}$ Per Mouritsen, "Four Models of Republican Liberty and SelfGovernment ", dans Iseult Honohan et Jeremy Jennings, dir., Republicanism in Theory and Practice, New York, Routledge, 2006, p. 19.

${ }^{28}$ Mouritsen, « Four Models of Republican Liberty », p. 19-20.

${ }^{29}$ John Gray, Liberalism, Milton, Open University Press, 1986, p. x.

${ }^{30}$ L'objectif de ces ateliers, qui furent créés le 26 février 1848, était de remplir la promesse du gouvernement provisoire d'offrir des emplois à tous les citoyens. Les hommes sans emploi pouvaient s'inscrire pour travailler dans leur arrondissement, où ils recevaient un peu plus de la moitié du salaire quotidien des ouvriers parisiens pour apporter leur concours sur des chantiers de construction (William Fortescue, France and 1848: The End of Monarchy, New York, Routledge, 2005, p. 96-97).

${ }^{31}$ Fortescue, France and 1848, p. 66-75. Pour une étude plus approfondie, voir R. J. W. Evans et al., dir., The Revolutions in Europe, 1848-1849: From Reform to Reaction, Oxford, Oxford University Press, 2000 ; Dieter Dowe et al., dir., Europe in 1848: Revolution and Reform, trad. David Higgins, New York, Berghahn Books, 2001 ; Pierre Lévêque, Révolutions et républiques : la France contemporaine, Dijon, Éditions Universitaires de Dijon, 2005 ; Axel Körner, dir., 1848-A European Revolution? International Ideas and National Memories of 1848, Londres, Macmillan Press, 2000. La seule autre étude portant sur l'incidence des révolutions européennes de 1848 sur l'Amérique du Nord et l'Amérique du Sud, à l'exclusion du Canada, se trouve dans Guy Thomson, dir., The European Revolutions of 1848 and the Americas, Londres, Institute of Latin American Studies, 2002, $240 \mathrm{p}$.

${ }^{32}$ Jonathan Sperber, The European Revolutions, 1848-1851, Cambridge, Cambridge University Press, 2005, p. 236.

${ }^{33}$ Il n'est pas inutile de noter que les concessions accordées par CharlesAlbert, roi de Piémont-Sardaigne, dans sa charte, le «Statuto Albertino », ont été maintenues et ont contribué à l'établissement ultérieur du parlementarisme en Italie (Angelica Gernert, «Italien 1848-Revolution auf italienisch », dans Heiner Timmermann, Berlin, Duncker \& Humblot, dir., 1848 Revolution in Europa: Verlauf, politische Programme, Folgen und Wirkungen, Berlin, Duncker \& Humblot 1999, p. 279).

${ }^{34}$ Ce court résumé des révolutions européennes de 1848 est tiré de Sperber, The European Revolutions, p. viii-xx. 
${ }^{35}$ Hayden White, « The Historical Text as Literary Artifact », dans G. Roberts, dir., The History and Narrative Reader, Londres, 2001 (1974), p. 230.

${ }^{36}$ « Révolution en France », L'Avenir, 22 mars 1848, p. 2, col. 2.

${ }^{37}$ Roger Price, dir., 1848 in France, Ithaca, Cornell University Press, 1975, p. 182-185.

${ }^{38}$ Jacques-Allain de Séduoy, Le comte Molé, ou, la séduction du pouvoir, Paris, Perrin, 1994, p. 17.

39) « Révolution en France », L'Avenir, 22 mars 1848, p. 2.

${ }^{40}$ "Indépendance du parlement ", L'Avenir, 28 octobre 1848, p. 1.

${ }^{41}$ « Révolution en Irlande », L'Avenir, 8 avril 1848, p. 7, col. 2.

${ }^{42}$ Ibid.

${ }^{43}$ Ibid.

${ }^{44}$ « Détails sur la révolution en Allemagne », L'Avenir, 22 avril 1848, p. 4, col. 2 .

${ }^{45}$ « Révolution en Irlande », L'Avenir, 8 avril 1848, p. 7, col. 3.

46 Louis-Joseph Papineau, "Assemblée du marché Bonsecours », L'Avenir, 15 avril 1848 , p. 2 , col. 3 .

${ }^{47}$ Ibid.

${ }^{48}$ Ibid., p. 3, col. 2.

49) Ibid.

${ }^{50}$ Ibid.

${ }^{51}$ "L'Union et la nationalité », L'Avenir, 3 mai 1848, p. 3, col. 2.

${ }^{52}$ « L'Union et la nationalité : La Minerve », L'Avenir, 6 mai 1848, p. 1, col. 3.

${ }^{53}$ Fortescue, France and 1848 , p. 125-126.

${ }^{54}$ « Nouvelles d'Europe », L'Avenir, $1^{\text {er }}$ juillet 1848, p. 3, col. 2.

${ }^{55}$ L'Avenir, 12 juillet 1848, p. 4, col. 1.

56 La Revue des Deux Mondes était un journal philosophique et littéraire français qui n'avait pas de position éditoriale définie en matière politique (Samuel, L'image de la Révolution en France, p. 34).

${ }^{57}$ Cité dans « Nouvelles d'Europe », L'Avenir, 19 juillet 1848, p. 3, col. 2. 
5* «Nouvelles d'Europe », L'Avenir, 19 juillet 1848, p. 3, col. 2

5" Armand Marrast fut maire de Paris au cours du premier gouvernement provisoire formé après la révolution française de 1848. Il fut l'un des membres les plus conservateurs de ce gouvernement, s'efforçant principalement de restaurer la loi et l'ordre après la révolution (Fortescue, France and 1848, p. 80-88).

${ }^{61)}$ Le 15 mai 1848, un groupe important de manifestants dirigés par des clubs révolutionnaires parisiens pénétrèrent dans l'Assemblée nationale dans l'intention de perturber les débats prévus sur la Pologne. Après une période de confusion, un des chefs de club proclama la dissolution du gouvernement et les manifestants se portèrent immédiatement à l'hôtel de ville pour y proclamer l'instauration d'un nouveau gouvernement révolutionnaire. Néanmoins, ils furent rapidement dispersés par les forces gouvernementales (Peter Amann, "A “journée" in the Making: May 15, 1848 », Journal of Modern History 42, $\mathrm{n}$ " 1 [1970], p. 44.).

${ }^{61}$ «Nouvelles d'Europe », L'Avenir, 19 juillet 1848, p. 3, col. 2.

${ }_{6.2}^{1}$ Ibid.

${ }^{63}$ L'Avenir, 12 juillet 1848, p. 4, col. 1.

${ }^{64}$ «Nouvelles d'Europe », L'Avenir, 15 juillet 1848, p. 3, col. 1.

${ }^{65}$ "A la Ruche Populaire », L'Avenir, 4 novembre 1848, p. 2, col. 4.

${ }^{66}$ L.-A. Dessaulles, "Assemblée d'Yamachiche ", L'Avenir, ${ }^{\text {er }}$ juillet, p. 1, col. 3.

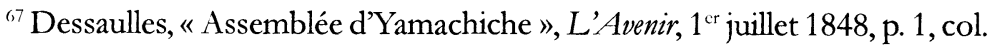
3.

${ }^{68}$ "La France », L'Avenir, 30 septembre 1848, p. 1, col. 2.

(1) «La France », L'Avenir, 30 septembre 1848, p. 1, col. 3.

${ }^{70}$ «Le nouveau programme ministériel », L'Avenir, 4 octobre 1848, p. 2, col. 1.

${ }^{71}$ Ibid.

${ }^{72}$ Mouritsen, « Four Models of Republican Liberty », p. 26 (soulignés dans le texte).

${ }^{73}$ Ibid., p. 27.

${ }^{74}$ Ibid., p. 28. 


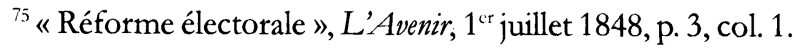

$7^{76}$ " La Minerve et l'opposition politique », L'Avenir, 5 août 1848, p. 2, col. 5. L'expression « les quatre poteaux» fait référence aux quatre journaux ministériels.

${ }^{77}$ Ibid.

${ }^{78}$ Ibid.

79 "Le Journal de Québec », L'Avenir, 16 décembre 1848, p. 2, col. 3.

sil Ibid.

${ }^{81}$ Ibid.

${ }^{82}$ Ibid.

${ }^{83}$ Voir Isaiah Berlin, Four Essays on Liberty, Londres, Oxford University Press, 1969, p. 121.

${ }^{84}$ «L'union, la nationalité : Le Journal de Québec », L'Avenir, 20 mai 1848, p. 3 , col. 2 .

${ }^{85}$ Le chartisme, un mouvement de réformes sociales et politiques, vit le jour en Angleterre dans les années 1830. Deux de ses principaux chevaux de bataille étaient le suffrage universel et le scrutin secret. Pour une interprétation " républicaine » du chartisme voir Gareth Stedman Jones, "Rethinking Chartism ", Language of Class: Studies in English Working Class History, 18321982, Cambridge, Cambridge University Press, p. 198.

${ }^{86}$ L'Avenir, 16 août 1848, p. 1, col. 4.

${ }^{87}$ Ibid.

${ }^{88}$ "Dîner donné aux collaborateurs de l'Avenir », L'Avenir, 2 septembre 1848, p. 2, col. 1 .

${ }^{89}$ Ibid.

${ }^{\text {x) }}$ Fait intéressant, ce changement fut même signalé dans la section des publicités commerciales de L'Avenir. L. Plammond, un marchand de vêtements au 122, rue Saint-Paul, y fit passer pendant la première moitié de l'année 1848 une annonce dont le titre était "progrès de la révolution". Il utilisait un langage révolutionnaire élaboré pour vendre ses articles. Le sous-titre - « république proclamée au milieu des hardes faites. Le gouvernement provisoire de la maison Plammond au peuple du Canada »-exploitait l'espoir d'une révolution dans le Bas-Canada. Il promettait, entre autres changements, 
« d'opérer une révolution complète dans les prix des hardes », suite à la disparition de tous les monopoles et privilèges. (L'Avenir, 17 mai 1848, p. 4, col. 12). Néanmoins, le 20 septembre 1848, en même temps que le changement d'opinion de L'Avenir à l'égard de la révolution, le titre de l'annonce fut changé pour " progrès des réformes radicales » et la proclamation de l'instauration de la république disparut. (L'Avenir, 20 septembre 1848, p. 3, col. 4-5). De plus, le marchand promettait maintenant « d'opérer une réforme radicale dans les prix " parce que les monopoles disparaissaient petit à petit (L'Avenir, 20 septembre 1848, p. 3, col. 4-5). Les changements d'approche publicitaire témoignent du revirement idéologique qui s'était opéré à L'Avenir en septembre 1848. Afin que son annonce demeure accrocheuse, le marchand se sentit obligé de s'aligner sur la vision républicaine d'une révolution sans violence dans le Bas-Canada.

"1 Frédéric Gaillardet, « France », L'Avenir, 31 octobre 1849, p. 1, col. 1.

${ }^{92}$ Ibid.

"3. Cet extrait de La Ruche populaire fut cité dans « La Propriété », L'Avenir, 11 novembre 1848, p. 1, col. 1.

${ }^{94}$ Samuel, L'image de la Révolution en France, p.34.

${ }^{25}$ « Nouvelles d'Europe », L'Avenir, 10 janvier 1849, p. 2, col. 5.

Eugène Hatin, Histoire politique et littéraire de la presse en France, vol. 8, 1861 (réimpression, Genève, Slatkine Reprints, 1967, p.604).

${ }^{97}$ « Nouvelles d'Europe », L'Avenir, 10 janvier 1849, p. 2, col. 5.

${ }^{98}$ Ibid.

" " Nouvelles d'Europe », L'Avenir, 10 février 1849, p. 3, col. 4.

${ }^{100} \mathrm{Ibid}$.

${ }^{101}$ « Nouvelles d'Europe », L'Avenir, 18 octobre 1848, p. 3, col. 2.

${ }^{102}$ «Le Canada », L'Avenir, 11 novembre 1848, p. 2, col. 1.

${ }^{103} \mathrm{Ibid}$.

${ }^{104}$ «Le 24 février », L'Avenir, 24 février 1849, p. 3, col. 4.

${ }^{105} \mathrm{Ibid}$.

${ }^{106} \mathrm{Ibid}$.

${ }^{1117}$ « Nouvelles d'Europe », L'Avenir, 10 février 1849, p. 3, col. 4. 
${ }^{108}$ Ibid.

${ }^{10 \%}$ « Nouvelles d'Europe », L'Avenir, 8 novembre 1848, p. 3, col. 2.

${ }^{110}$ "Le 24 février », L'Avenir, 24 février 1849, p. 3, col. 4.

${ }^{111}$ Ibid.

112 Ibid.

113 Ibid.

${ }^{114}$ Ibid. 